\title{
LA ENSEÑANZA DE LA ANTROPOLOGÍA EN EL SISTEMA EDUCATIVO: RETOS Y DESAFIIOS ACTUALES
}

Ana Silvia Ortiz Gómez

Investigadora, IEHAA-UES

Agradezco la invitación del Centro Nacional de Investigaciones en Ciencias Sociales (CENICSH) del Ministerio de Educación (MINED) a participar en este conversatorio, en el que expondré algunas reflexiones a partir de mi experiencia como integrante del núcleo de expertos que implementamos el Módulo IV "Sociedad, cultura e identidades" de la especialidad en Ciencias Sociales, en el marco del Plan Nacional de Formación de Docentes en Servicio del Sector Público.

Esta mañana propongo reflexionar sobre la diversidad sociocultural de la sociedad salvadoreña como un tema relevante para los programas de estudio y la necesidad de contar con un planteamiento didáctico metodológico para tratar el ejercicio investigativo en las aulas. ¿Por qué estos planteamientos y no otros? Porque durante mi participación como experta en el proceso de formación docente para profesorado de tercer ciclo y nivel medio superior en San Vicente, éstos tópicos fueron considerados relevantes para el propio profesorado en formación. Aclaro que su abordaje no pre- 
tende ser exhaustivo, más bien un punto de partida para conversar sobre los retos y desafios de la enseñanza de Antropología en el sistema educativo.

Iniciaré presentando el objetivo y las temáticas a desarrollar en el Módulo IV "Sociedad, cultura e identidades". Segundo, argumentaré porque el abordaje de la diversidad sociocultural es relevante para la construcción de ciudadanía. Tercero, problematizaré la inquietud por clarificar el sentido del ejercicio investigativo en antropología que se plantea como parte del proceso formativo de los docentes. Concluiré, con algunas valoraciones sobre la relevancia que tiene la incorporación de la Antropología en el proceso de formación docente y el reto de construir una visión interdisciplinaria que sustente dicho proceso.

\section{¿Qué temáticas nos propuso el módulo de antropología?}

El Plan Nacional de Formación de Docentes trazó como objetivo del Módulo IV Sociedad, cultura e identidades "fortalecer la formación en el dominio de la antropología como componente fundamental de las ciencias sociales, en materia de formación de los sistemas culturales e identidades salvadoreñas para el desarrollo de las competencias ciudadanas y de procesos de convivencia social en el contexto de una sociedad globalizada”. El módulo se distribuyó en cuatro unidades que trataron: los conceptos básicos de esta disciplina y su vínculo con otras ciencias sociales; las identidades salvadoreñas en un contexto centroamericano y mesoamericano; las migraciones en el marco de la globalización; y la dimensión sociocultural de la violencia social.

El núcleo de personas expertas encargadas de desarrollar el módulo lo integramos antropólogas, antropólogos y arqueólogos formados dentro del país (Universidad Tecnológica de El Salvador) y en el extranjero (México, Canadá, España, Estados Unidos) lo que aportó pluralidad al debate de las temáticas propuestas por el MINED y que responden a las diversas tradiciones antropológicas en las que hemos sido formados; lo cual hace de 
este núcleo un espacio de encuentro disciplinar privilegiado. Lo cual nos restó que cada experto le añadiera su "estilo personal" al acercamiento de los temas en el aula, dadas nuestras diversas experiencias de docencia, investigación y gestión cultural.

\section{¿Por qué la reflexión de la diversidad de las identi- dades socioculturales de la sociedad salvadoreña es relevante para la construcción de ciudadanía?}

Si atendemos la necesidad de dotar de temas y contenidos fundamentales a los programas de estudio para la construcción de una ciudadanía que Adela Cortina caracteriza como "impregnada de virtudes cívicas, muy dispuesta a involucrarse en la vida pública, a trabajar en la vida pública" ¿Qué capacidades deben formarse en el aula para impulsar un cambio profundo en las actitudes y conductas que conduzcan a una sociedad donde prevalezca la justicia, la democracia, la equidad, solidaridad y el respeto por las diferencias?

El módulo IV al plantear la diversidad sociocultural de la sociedad salvadoreña cuestiona la idea fuertemente arraigada en el imaginario colectivo de una única identidad nacional, con lo que puede contribuirse a cimentar una convivencia social que si bien reconoce y comprende las diferencias socioculturales, no fomenta que éstas deriven en desigualdad y la exclusión social.

Carlos Lara señala que si bien los orígenes de la construcción de la identidad nacional salvadoreña se encuentran en los intereses de la elite añilera de finales de la colonia, su configuración no pude ubicarse antes de finales del siglo XIX. Para Heriberto Erquicia el proyecto de construcción de identidad nacional por parte del Estado salvadoreño y que se centró en ideas como el mestizaje - invisibilizando a las poblaciones indígenas contemporáneas y la exaltación de los vestigios arqueológicos como símbolo de un pasado prehispánico glorioso-, encontró en los maestros y en las instituciones educativas actores y espacios de socialización y legitimación. En 
2016 son de nuevo los centros educativos y el profesorado en los que recae, en gran parte, la tarea de desarrollar programas educativos que proporcionen conocimientos sobre la coexistencia en el país de diversos sistemas socioculturales, con base en los cuales diría Carlos Lara " se pueden generar diversos modelos de desarrollo social, que respondan a las aspiraciones y los anhelos profundos de los sujetos sociales" y que orienten "la construcción de un nuevo tipo de sociedad y de cultura, una sociedad más equitativa, solidaria y que favorezca la participación ciudadana".

La comprensión de las dinámicas socioculturales y su relación con la marginación de amplios sectores de la población salvadoreña (indígenas, personas transgénero, pandillas, niños y niñas en condición de calle, entre otros), requiere de transitar de la enseñanza de la cultura y la identidad desde la óptica culturalista (centrada en el estudio de la cultura popular bajo el concepto de folklore) hacia una perspectiva simbólica. Al respecto Gilberto Giménez al parafrasear a Clifford Geertz, nos dice que la cultura son "pautas de significados"; lo que Weber denomina "telaraña de significados" eso "que nosotros mismos tejemos a nuestro alrededor y dentro de la cual quedamos ineluctablemente atrapados".

Desde esta perspectiva Lara Martínez propone superar la identificación sociocultural a partir de criterios biologicistas, culturalistas y sociologistas, y se decanta por una perspectiva relacional "en la que intervienen al menos dos sujetos sociales: nosotros - el grupo portador de una identidad determinada - y los otros - el grupo (o los grupos) con el que aquél entra en contacto cotidiano-, en donde los otros son considerados como los extraños, los diferentes a nosotros. Esta relación social, que es una relación de oposición y contraste, constituye la base a partir de la cual el grupo construye un sistema de relaciones sociales que integra a sus miembros y un sistema cultural, esto es, un sistema de normas y valores sociales que orienta la vida cotidiana de éstos"

Justamente en San Vicente la mayoría de los equipos de investigación optaron por investigar la conformación y socialización de identidades 
socioculturales en los entornos educativos, tales como: pandillas juveniles, otakkus $^{1}$, frikis ${ }^{2}$ y por indagar en el uso de tecnología y el acceso al mundo virtual como un factor identitario entre los jóvenes.

\section{¿Cuál es el sentido del ejercicio investigativo en antropología?}

Si como núcleo de expertos nos posicionamos en la enseñanza de la antropología simbólica y como parte de este aprendizaje inducimos un proceso de investigación, es importante reflexionar cómo en 8 jornadas presenciales (de 8 horas cada una), más las asesorías virtuales desarrollamos una base teórica -metodológica "mínima” que les permita a los docentes en formación realizar trabajo de campo etnográfico (entendido éste como la interacción cotidiana y prolongada con nuestros sujetos de estudio) y las etapas de sistematización, análisis e interpretación de los datos.

El grupo de profesores y profesoras con los que trabajé en San Vicente demostraron un interés genuino y asombro por los lentes teóricos que la Antropología les brindó para comprender temas que les son significativos por sus historias personales y familiares, como son la emigración de connacionales hacia EU en condiciones de vulneración de sus derechos humanos y la lógica de la violencia pandilleril.

No obstante, manifestaron su preocupación porque en sus centros escolares no contaban con el apoyo institucional para acudir entre semana a realizar el trabajo de campo a los centros escolares que eligieron como universo de estudio, por lo que tuvieron que hacerlo en horarios que no chocaran con sus responsabilidades laborales, al grado de que varios pidieron

\footnotetext{
${ }^{1}$ Aficionados a la cultura oriental y sus valores y manifestaciones, como el anime, el respeto a la naturaleza y la diversidad sexual.

${ }^{2}$ Amantes de la lectura, que se consideran cultos pero cool. Llama la atención una estudiante de primer año de bachillerato, quién contó que desde que cursaba octavo grado, una tía le indujo a la lectura y desde entonces hasta el momento de la conversación, ha concluido ciento quince libros, de los cuales lleva un pequeño registro.
} 
un día de permiso personal. Obviamente, urge una sensibilización de las autoridades al frente de los centros educativos en los que laboran los docentes en formación para que faciliten el trabajo de campo etnográfico.

Y más allá de resolver la logística del trabajo de etnográfico, es importante preguntarse: ¿Cómo organizar las ocho jornadas del módulo para dejar más tiempo al trabajo metodológico que todo proceso de investigación requiere? Como núcleo de expertos debemos preguntarnos: ¿Estamos “ajustando" la metodología de investigación empleada en las universidades en qué laboramos a un proceso de 8 jornadas?¿Qué es lo deseamos? ¿Qué los docentes tengan nociones generales de la investigación antropológica o generar procesos de investigación dónde el método etnográfico sea uno de los tantos que pueden retomar de la Ciencias Sociales para la investigación del entorno escolar? ¿No será que estamos ante la ausencia de planteamiento didáctico metodológico por parte del núcleo de expertos? Como verán en este tópico son más mis dudas que las certezas.

\section{Relevancia de la Antropología en el replanteamiento del currículo nacional}

El Plan Nacional de Formación de Docentes busca fortalecer la formación en "Ciencias Naturales, Lenguaje, Literatura, Matemáticas, Ciencias Sociales, así como Química, Física, Biología, Inglés, Arte y Cultura" del profesorado en activo, para que en su momento sean éstos los que participen en el replanteamiento del currículo nacional, el cual se orientará a la formación de capacidades ciudadanas, es decir, de habilidades, competencias y capacidades cognitivas, emocionales y comunicacionales para plantearse problemas socialmente relevantes, así como alternativas de solución.

A todas luces el reto del nuevo currículo nacional será construir una formación educativa interdisciplinaria que atienda problemas a partir de variados enfoques disciplinares ¿Qué podría aportar la antropología a la comprensión de los problemas educativos? Salvando las distancias históricas 
y socioculturales, la española Aurora Bernal nos aporta pistas, al señalar que la antropología de la educación puede contribuir en: 1) la divulgación en la sociedad nacional de la diversidad sociocultural mediante encuentros, foros, exposiciones, noticias, visitas a museos; 2) en el análisis de cómo se realizan los procesos educativos en relación con el contexto sociocultural, por ejemplo en cómo los planteamientos morales y los valores inciden en los fines educativos de un grupo; 3) en compaginar el conocimiento de mecanismos de aprendizaje con el estudio de las formas de aculturación en la familia, grupos de iguales por edad, género, trabajo, instituciones educativas formales y no formales, entre otros.

Para concluir quiero enfatizar en tres puntos:

1.- La enseñanza de la diversidad de las identidades socioculturales en la sociedad salvadoreña, al cuestionar la idea de una única identidad nacional, puede contribuir a cimentar una ciudadanía que si bien reconoce y comprende las diferencias socioculturales, no fomenta que éstas deriven en desigualdad y exclusión social.

2.- La necesidad de reflexionar para qué se realiza la práctica investigativa en Antropología: ¿Para dotar a los docentes en formación de nociones generales de la investigación antropológica o para generar procesos de indagación dónde el método etnográfico sea una herramienta más de las Ciencias Sociales para la investigación del entorno escolar? ¿Requerimos como núcleo de expertos de renovar nuestros planteamientos didácticos metodológicos para hacer frente a este reto?

3.- Promover el diálogo intradisciplinar sobre cómo la antropología puede aportar en la construcción interdisciplinaria de un nuevo currículo nacional que atienda los problemas educativos desde una perspectiva holística. 